\title{
Characterisation of secondary metabolites from Rhinacanthus nasutus L (Kurz) for the identification of novel antibacterial leads
}

\author{
Sheikh, H.M. ${ }^{1,2 *}$ and Reshi, N.A. ${ }^{3}$ \\ ${ }^{1}$ Department of Biological Science, Faculty of Science and Arts, King Abdulaziz University, Rabigh Campus, \\ P.O. Box 344, 21911 Rabigh, Saudi Arabia \\ ${ }^{2}$ Biology Department, Faculty of Science, University of Jeddah, P.O. Box 80327, Jeddah, 21589, Saudi Arabia \\ ${ }^{3}$ Department of Botany, School of Science, Sandip University, Nashik, Maharashtra, 422 213, India \\ *Corresponding author e-mail: hmsheikh@kau.edu.sa \\ Received 24 December 2018; received in revised form 20 August 2019; accepted 2 September 2019
}

\begin{abstract}
The bioactivity of $R$. nasutus leaf extracts was assessed on Bacillus cereus, Bacillus subtilis, Staphylococcus aureus, Streptococcus pyogenes, Vibrio parahaemolyticus, Enterobacter aerogenes, Proteus mirabilis, and Klebsiella pneumoniae. Crude chloroform, petroleum ether, ethyl acetate, ethanol and methanol extracts were screened by disc diffusion method. Promising crude extract was further subjected to the column fractionation followed by the screening of the antibacterial activity of individual fractions. Biologically active pure fraction was subjected to the advanced analytical studies like HPLC, LC-MS, IR and NMR for characterisation of the bioactive compound. Ethanolic extract exhibited the maximum antibacterial activity against Klebsiella pneumoniae with the maximum of $35 \pm 0.42 \mathrm{~mm}$ zone of inhibition. The biologically potent column fraction from ethanol extract with $40 \pm 0.42 \mathrm{~mm}$ zone of inhibition upon subject to the HPLC, LC-MS, IR and NMR revealed that the active compound is rhinacanthin-C, a naphthoquinone.
\end{abstract}

\section{INTRODUCTION}

Ever since the existence of life there has been an endless encounter between humans and the infectious microorganisms. Major advancement in the antibiotic developments in the $20^{\text {th }}$ century helped turn the tide in favor of humans and with the discovery of penicillin in early 1940 s the situation drastically improved with respect to the bacterial diseases (Magiorakos et al., 2012). However, the ecstasy over potential defeat of infectious disease had a short existence. Almost as soon as antibacterial drugs were deployed, bacteria started developing various forms of resistance against the available drugs. With the increased usage of antibacterials, the bacterial pathogens exhibited higher levels of complexity of resistance against the available antibiotics (Shah et al., 2007).
There has been a continuous struggle to gain the upper hand against deadly infectious microorganisms and despite the advancements in antibiotic research in the recent past, development of drug resistance is a grave and grim threat due to the scarcity in the contemporary drug development pipeline which are effective against vancomycin-resistant Klebsiella pneumoniae, multidrug resistant (MDR) Streptococcus pneumoniae, methicillinresistant Staphylococcus aureus (MRSA), $\beta$-lactamase producing Gram-negative bacteria or MDR and extensive-drug resistant (XDR) strains of Mycobacterium tuberculosis (Pillay et al., 2007). The development of resistance is attributed to the widespread overuse and over-the-counter (OTC) availability of antibiotics. The present situation is fostering prospective research 
to identify the new biologically viable natural molecules from the traditional medicine.

The increasing prevalence of drug resistant bacteria has pressed hard on scientific communities to look for potential antibacterial agents of plant origin, which are considered as untapped diverse source of chemicals. Plants are considered as treasure house of biologically active principles which makes them viable source of different remedies (Tadeg et al., 2005). Contrary to the synthetic drugs, antimicrobials of plant origin are devoid of any side effects and have tremendous curative potential to heal infectious diseases. Many attempts have been made to unfold the new antimicrobials from different natural resources such as microorganisms, animals and plants. Till date, approximately $20 \%$ of the medicinal plants worldwide have been explored to identify and unravel their biologically active compounds (Sukanya et al., 2009). Bioprospecting of traditionally used medicinal plants forms the basis of drug discovery.

Rhinacanthus nasutus belongs to the family Acanthaceae (shrub, 1-2 cm in height) and is extensively used in the traditional medicine of India. The plant grows in India, Taiwan, Thailand, and South Africa. Leaves and roots of this plant are extensively used for the treatment of various diseases (Wu et al., 1988). Traditionally, it is used to treat cancer, rheumatism (Kupradinun et al., 2009), pulmonary tuberculosis, peptic ulcers and scurvy (Sendl et al., 1996), antimicrobial activity (Puttarak et al., 2010), antiantidiabetic activity (Upendra et al., 2010).

\section{MATERIALS AND METHODS}

$R$. nasutus plants were collected from the Nilgiri Hills, Western Ghats of Tamil Nadu, India and are being maintained in the medicinal plant garden of Department of Botany, Sandip University, Nashik, India. Leaves were shade dried and coarse powdered using electric homogeniser. Solvent extraction of plant material was carried out by taking 25 grams of dry leaf coarse powder in a thimble and extracted sequentially with $200 \mathrm{ml}$ of petroleum ether, chloroform, ethyl acetate, ethanol and methanol in Soxhlet extractor for 48 hours (Hawthorne et al., 2000). The solvent extracts were concentrated under reduced pressure and were stored at $5^{\circ} \mathrm{C}$ in vials for further use. The test bacteria were; Gram-positive bacteria: Streptococcus pyogenes (MTCC 422), Staphylococcus aureus (MTCC 1144), Bacillus subtilis (MTCC 441), Bacillus cereus (MTCC 430). Gram-negative bacteria: Klebsiella pneumoniae (MTCC 7407), Proteus mirabilis (ATCC 7002), Enterobacter aerogenes (MTCC 111) and Escherichia coli (MTCC 1687). All the test microorganisms were procured from MTCC Chandigarh, India. The preliminary antibacterial activity was screened by Disc Diffusion Method (Drew et al., 1972). The extract showing the promising antibacterial activity was subjected to the column fractionation using methanol and $5 \%$ aqueous acetic acid (80:20, v/v) as the mobile phase (Ignat et al., 2011). The individual fractions were further confirmed on TLC followed by screening of antibacterial activity of pure fractions by disc diffusion method (Drew et al., 1972). The pure fraction with the maximum inhibition potential was subjected to the HPLC, LCMS, IR and NMR for the structural elucidation. HPLC: Symmetric shield RP18 (150 mm x 3.9 mm x $5 \mu \mathrm{m}$ ) column was used. $10 \mathrm{mM}$ ammonium acetate and acetonitrile were used as mobile phase with the flow rate of $1 \mathrm{ml} / \mathrm{min}$. $2 \mathrm{mg}$ of extract sample was dissolved in DMSO and was injected into column at the volume of 10 $\mathrm{\mu l}$ and the column was run for 12 minutes. The sample analysis was carried out at room temperature and the chromatogram developed was used for further studies to elucidate the compound structure.

LC-MS: It was done using SPD 10 AVP - Shimdzu apparatus with column of phenomenex RP 18 of $25 \times 2.5$ dimensions. The mobile phase used was water: methanol (1:1), $20 \mu \mathrm{l}$ sample was injected with the flow rate of $2 \mathrm{ml} / \mathrm{min}$. The LC was detected at $265 \mathrm{~nm}$ using photo diode array detector. IR: The pin head size dry sample was placed on the detector and the IR was recorded. The 
main functional groups were identified by their characteristic vibrational frequencies (Kalsi, 2002). IR spectrum was recorded using PerkinElmer Spectrum IR spectrometer in the range of $4000-600 \mathrm{~cm}^{-1}$. Two types of NMR studies were carried out; Proton NMR ( ${ }^{1} \mathrm{H}-\mathrm{NMR}$ ) and Carbon NMR ( $\left.{ }^{13} \mathrm{C}-\mathrm{NMR}\right)$. NMR spectrometer of Bruker DR x 500 FT- NMR was used for analysis. The sample was dissolved in DMSO and was injected.

\section{RESULT AND DISCUSSION}

The zone of inhibition was measured in $\mathrm{mm}$ after 24 hours of incubation and the results revealed that all the leaf extracts inhibited the growth of both Gram negative and Gram positive bacteria. The zone of inhibition of different crude extracts is shown in Table 1. The maximum zone of inhibition was reported in ethanol extract against Klebsiella pneumoniae with $35 \pm 0.42 \mathrm{~mm}$ zone of inhibition. Ethanol crude extract upon column fractionation resulted in 4 elutes and each fraction was subjected to the TLC. Out of the four elutes tested for antibacterial activity, fraction 2 exhibited the maximum zone of inhibition of $40 \pm 0.42 \mathrm{~mm}$ (Table 2). The HPLC chromatogram of the active fraction showed two peaks (a major and a minor) and the peak which eluted at $3.32 \mathrm{~min}$ is predominate with the maximum absorbance at $200 \mathrm{~nm}$ (Fig. 1). The LCMS analysis reveals a major peak with a mass of 410.5026 (Fig. 2). The IR spectra reveal a broad and strong band at $3375.73 \mathrm{~cm}^{-1}$ indicating the presence of $-\mathrm{OH}$ group. The stretching vibrations are due to the presence of aliphatic and aromatic - $\mathrm{OH}$ groups at signals $2295.21 \mathrm{~cm}^{-1}$ and 2924.35 $\mathrm{cm}^{-1}$. The stretching vibrations of aromatic rings at $1545.12 \mathrm{~cm}^{-1}$ suggest the presence of $\mathrm{C}=\mathrm{C}$. The presence of ester carbonyl group is indicated by intense absorption at 1726

Table 1. Inhibition Zone (mm) of leaf extracts against different Gram positive and Gram negative bacteria

\begin{tabular}{lcccccc}
\hline Pathogen & Ethanol & Methanol & E. Acetate & Pt. Ether & Chloroform & Streptomycin \\
\hline B. cereus & $19 \pm 0.63$ & - & - & $4 \pm 0.54$ & - & $40 \pm 0.55$ \\
B. subtilis & $22 \pm 0.65$ & $15 \pm 0.34$ & $5 \pm 0.45$ & - & $2 \pm 0.54$ & $35 \pm 0.65$ \\
S. pyogenes & - & - & - & - & - & $38 \pm 0.43$ \\
S. aureus & $27 \pm 0.65$ & $5 \pm 0.45$ & $12 \pm 0.45$ & $2 \pm 0.33$ & $3 \pm 0.58$ & $35 \pm 0.23$ \\
E. coli & $14 \pm 0.23$ & $2 \pm 0.65$ & - & - & - & $40 \pm 0.53$ \\
P. mirabilis & $15 \pm 0.28$ & $12 \pm 0.67$ & $3 \pm 0.62$ & - & - & $38 \pm 0.54$ \\
K. pneumoniae & $35 \pm 0.42$ & - & - & - & - & $35 \pm 0.56$ \\
E. aerogenes & $15 \pm 0.28$ & $4 \pm 0.53$ & - & - & - & $35 \pm 0.76$ \\
\hline
\end{tabular}

* Each test was repeated thrice. Each value represents Mean \pm S.D, statistical analysis done by DMRT $(\mathrm{P} \leq 0.5)$.

Table 2. Inhibition Zone (mm) of Ethanolic leaf extract fractions against different Gram positive and Gram negative bacteria

\begin{tabular}{lccccc}
\hline Pathogen & Fraction 1 & Fraction 2 & Fraction 3 & Fraction 4 & Streptomycin \\
\hline B. cereus & $15 \pm 0.23$ & $26 \pm 0.23$ & $5 \pm 0.23$ & $2 \pm 0.65$ & $40 \pm 0.53$ \\
B. subtilis & $10 \pm 0.28$ & $29 \pm 0.28$ & $12 \pm 0.28$ & $6 \pm 0.28$ & $38 \pm 0.54$ \\
S. pyogenes & $12 \pm 0.42$ & $30 \pm 0.42$ & $2 \pm 0.42$ & $10 \pm 0.42$ & $35 \pm 0.56$ \\
S. aureus & $8 \pm 0.28$ & $28 \pm 0.28$ & $3 \pm 0.28$ & $12 \pm 0.28$ & $35 \pm 0.76$ \\
E. coli & $5 \pm 0.23$ & $24 \pm 0.23$ & $8 \pm 0.23$ & $6 \pm 0.23$ & $40 \pm 0.53$ \\
P. mirabilis & $10 \pm 0.28$ & $15 \pm 0.28$ & $10 \pm 0.28$ & $3 \pm 0.28$ & $38 \pm 0.54$ \\
K. pneumoniae & $12 \pm 0.42$ & $40 \pm 0.42$ & $15 \pm 0.42$ & $6 \pm 0.42$ & $35 \pm 0.56$ \\
E. aerogenes & $15 \pm 0.28$ & $25 \pm 0.28$ & $12 \pm 0.28$ & $12 \pm 0.28$ & $35 \pm 0.76$ \\
\hline
\end{tabular}

${ }^{*}$ Each test was repeated thrice. Each value represents Mean \pm S.D, statistical analysis done by DMRT $(\mathrm{P} \leq 0.5)$. 


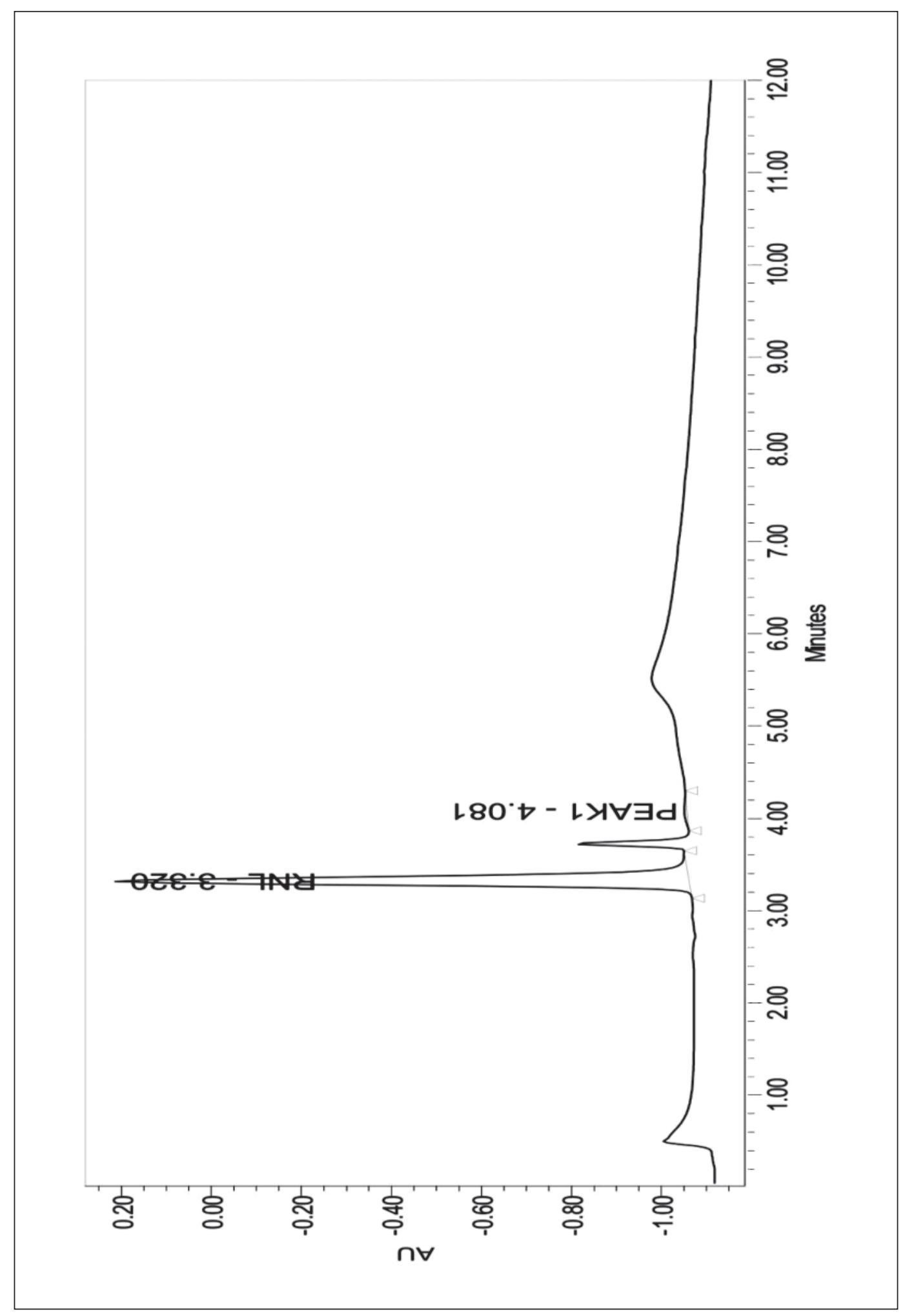

Figure 1. HPLC chromatogram of ethanolic leaf extract of $R$. nasutus. 


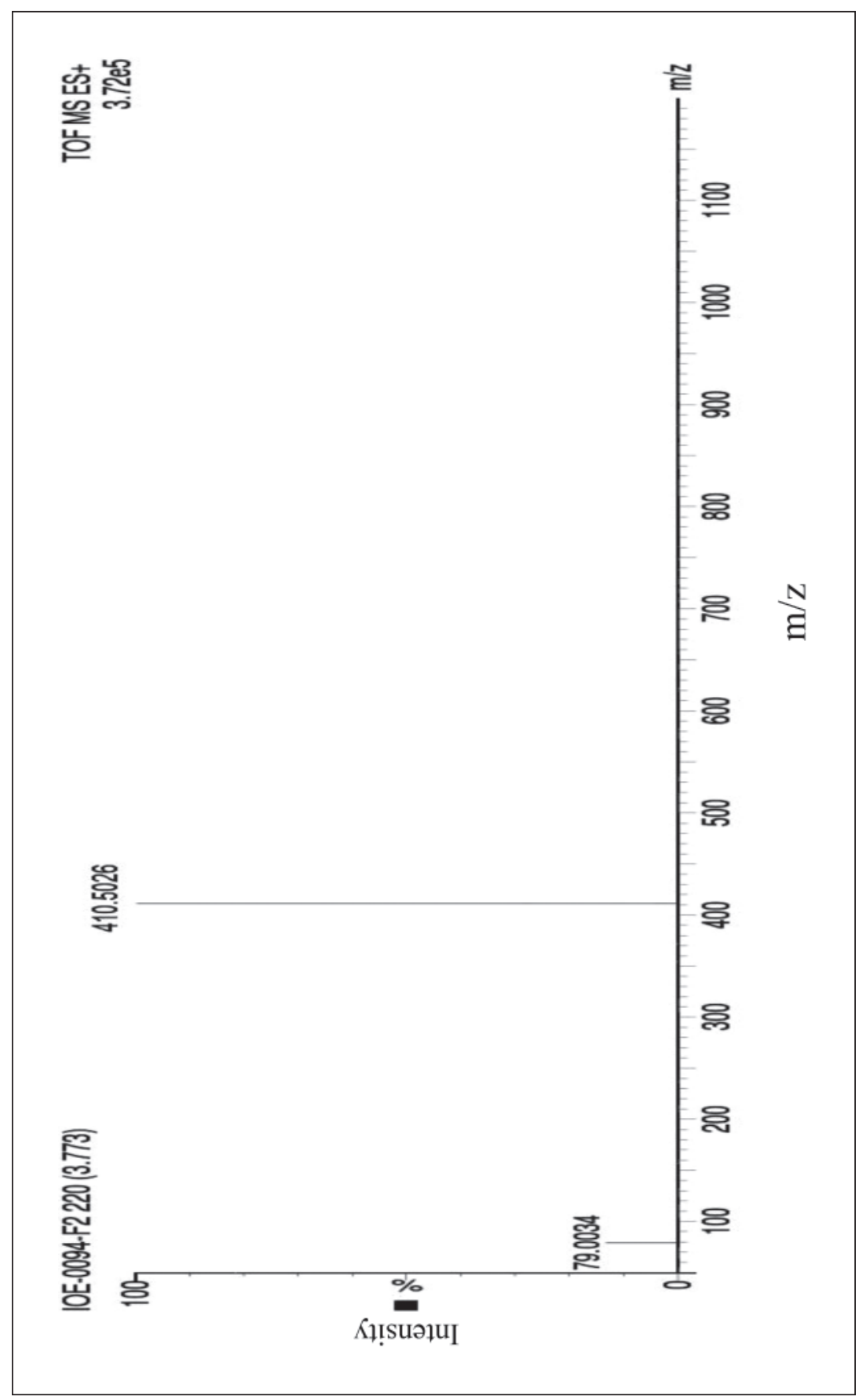

Figure 2. Mass spectrum of ethanolic leaf extract of $R$. nasutus.

$\mathrm{cm}^{-1}$. The spectrum also reveals the presence of $-\mathrm{CH}$ bending at $1462.17 \mathrm{~cm}^{-1}$ and $-\mathrm{CH}_{3}$ bending vibration at $1379.23 \mathrm{~cm}^{-1}$ (Fig. 3).

The proton NMR $\left({ }^{1} \mathrm{H}-\mathrm{NMR}\right)$ reveals the presence of 30 protons (six downfield signals, $\delta 5.82-8.71$; and eight up field signals, $\delta 1.02$
- 3.90). Signals at $\delta 8.98, \delta 8.26, \delta 7.99$ and $\delta 7.71$ suggest the naphthoquinone moiety. The signal at $\delta 6.67$ reveals the presence of olefinic proton attached to the methylene signal $(\delta 2.10)$ which in turn is attached to other methylene signal ( $\delta$ 2.05) (Fig. 4). In 


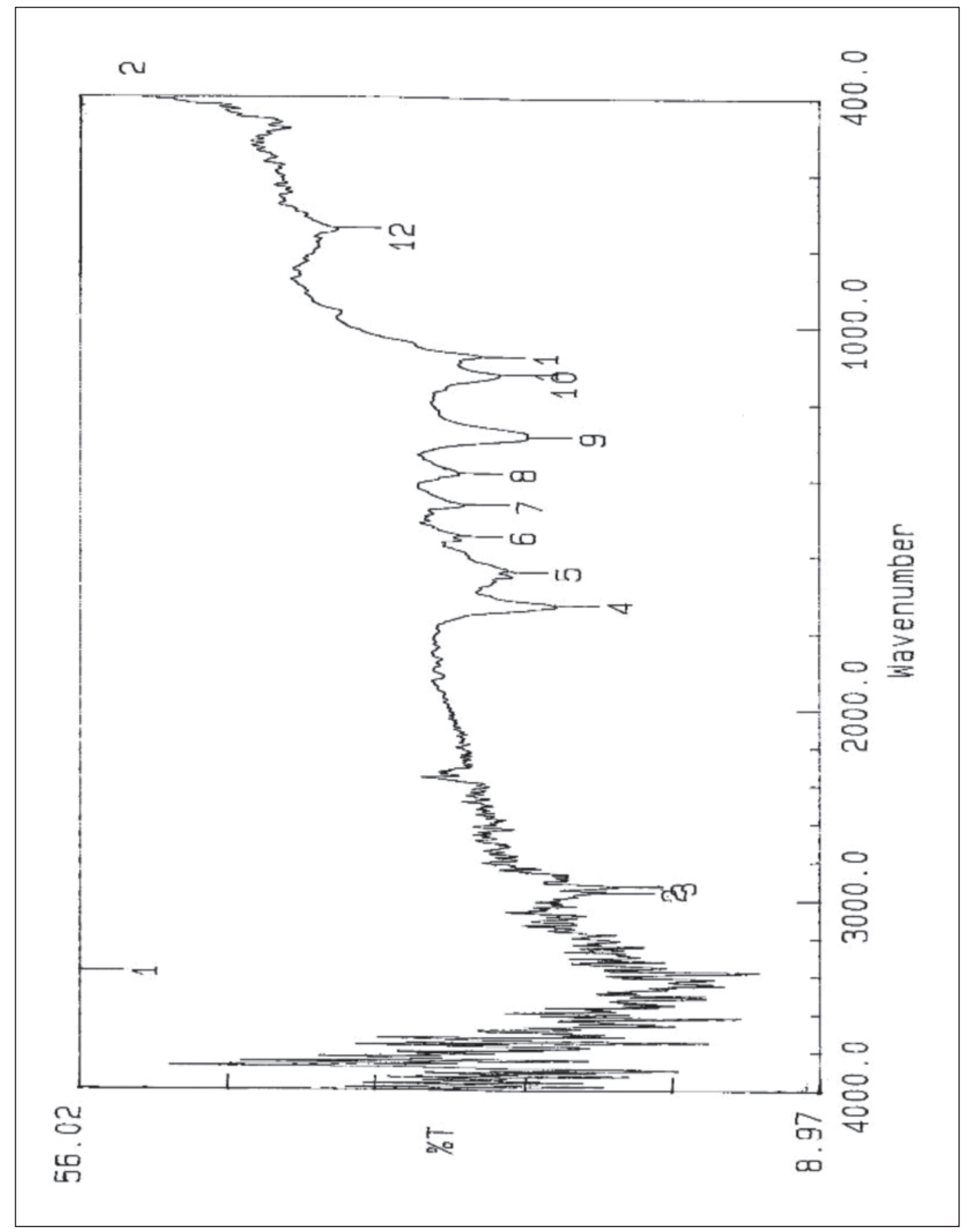

Figure 3. IR spectrum of ethanolic leaf extract of $R$. nasutus.

the ${ }^{13} \mathrm{C}-\mathrm{NMR}$ spectrum, signals at $\delta 142.95$, $\delta 134.65, \delta 131.65, \delta 133.65, \delta 132.95, \delta 128.45$, $\delta 128.26, \delta 127.65, \delta 126.98$ and $\delta 121.65$ are consistent and represent aromatic ring carbons. Presence of aliphatic carbons is revealed by signals at $\delta 71.75, \delta 55.62$, $\delta 37.12, \delta 35.34, \delta 33.25, \delta 26.54, \delta 26.64, \delta$ 14.35 and $\delta$ 13.23. Signal at $\delta 55.62$ reveals the presence of $\mathrm{C}-\mathrm{O}$ linkage in the spectrum. Signals at $\delta 187.35$ and $\delta 185.24$ suggest $C=O$ and the signal at $\delta 182.36$ represents ester carbonyl group (Fig. 5). The spectral analysis 


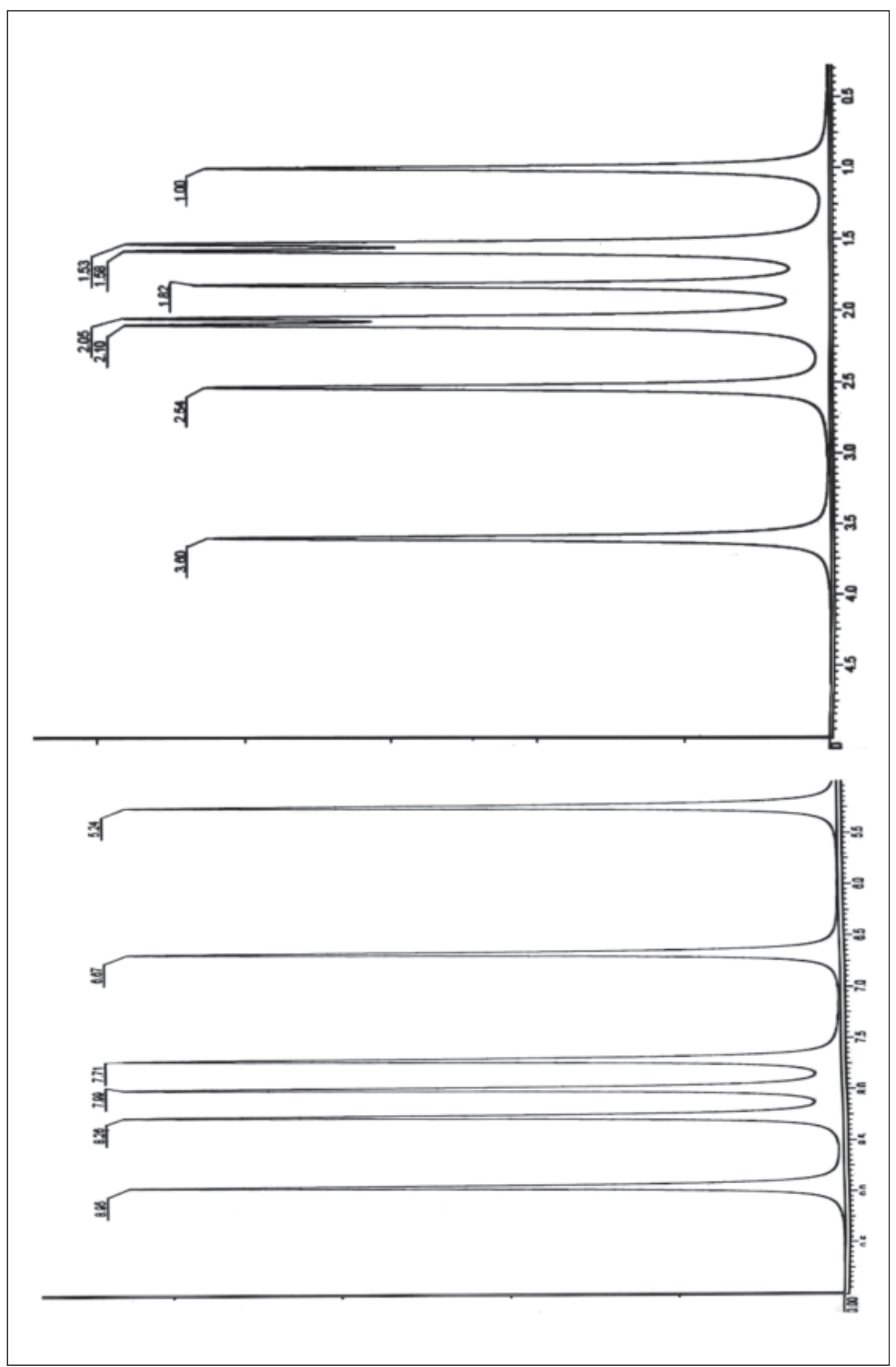

Figure 4. ${ }^{1} \mathrm{H}$ - NMR spectrum of ethanolic leaf extract of $R$. nasutus. 


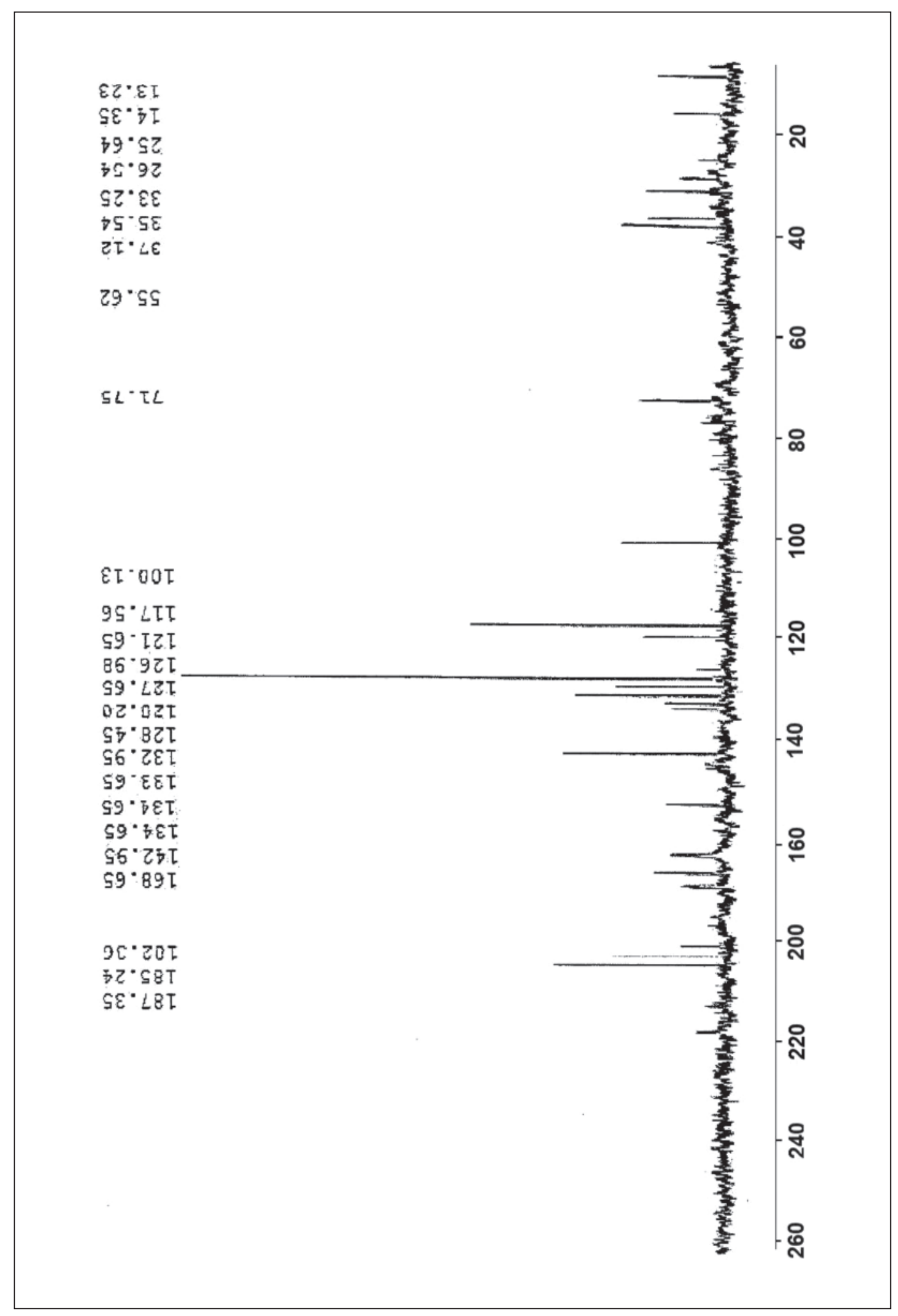

Figure $5 .{ }^{13} \mathrm{C}$ - NMR spectrum of ethanolic leaf extract of $R$. nasutus. 
of the ethanolic fraction provides the data percentage as; C (73.15\%), $\mathrm{H}$ (7.37\%) and $\mathrm{O}$ (19.49\%), which suggests the molecular formula as $\mathrm{C}_{25} \mathrm{H}_{30} \mathrm{O}_{5}$.

The molecular ion peak of the sample found at 410 also corresponds to the molecular formula as $\mathrm{C}_{25} \mathrm{H}_{30} \mathrm{O}_{5}$.

The purified compound has a spectral data alike to that of the rhinacanthin-C, a naphthoquinone, which has already been reported in earlier studies from the methanolic root extract of the same plant. The structure of the compound is as:<smiles>CC=C(C)CCC=C(C)C(=O)OCC(C)(C)CC1=C(O)C(=O)c2ccccc2C1=O</smiles>

\section{Structure of rhinacanthin-C}

The IUPAC name of the rhinacanthin-C is 3(3-hydroxy-1,4-dioxo-1,4-dihydronaphthalen2-yl)-2,2-dimethylpropyl (2E,6E)-2,6methylocta-2,6-dienoate.

Bioresources are considered as potentially diverse and rich resources of therapeutic agents. Phytoconstituents have a significant therapeutic property against diverse range of Gram positive and Gram negative bacteria (Lai and Roy, 2004). $R$. nasutus is extensively used in the ethnomedicine for the treatment of wide range of ailments including infectious diseases. The crude extract showed low antibacterial activity against the test bacteria compared to that of the individual pure fractions. This is attributed to the synergistic effect of the phytoconstituents. The same inference has been drawn by earlier authors (Thiyagarajan et al., 2011). In the present study, the purified compound has shown the potent antibacterial activity against K. pneumoniae. The pathogen has been reported to have developed the resistance against the available antibiotic methicillin. As our study has confirmed the presence of potent bioactive compound and hence makes a scope for the development of broad spectrum antibiotic. Our findings justify the use of this plant in traditional medicine. Due to the easy redox cycling capacity, quinonoid compounds are known for their wide range of antimicrobial potential (Brandelli et al., 2004). However, the potential antimicrobial property of quinonoid compounds has remained so far unexplored.

\section{CONCLUSION}

Phytoconstituents have played an important role in the lead drug discovery. In general, gram negative bacteria were more sensitive towards the crude extracts. The question remains to understand the mechanism of naphthoquinone antibacterial property and further in vivo studies need to carry out to strengthen the biological activity of the rhinacanthin-C.

Acknowledgement. This work was supported by the Deanship of Scientific Research (DSR), King Abdulaziz University, Jeddah, under grant No. (D-123-363-1439). The authors, therefore, gratefully acknowledge the DSR technical and financial support.

\section{Conflict of Interest}

Authors declare that they do not have any conflict of interest.

\section{REFERENCES}

Brandelli, A., Bizani, D., Martinelli, M., Stefani, V. \& Gerbase, A.E. (2004). Antimicrobial activity of 1, 4-naphthoquinones by metal complexation. Revista Brasileira de Ciências Farmacêuticas 40: 247-253.

Drew, W.L., Barry, A.L., Otoole, R. \& Sherris, J.C. (1972). Reliability of the Kirby-Bauer disc diffusion method for detecting methicillin-resistant strains of Staphylococcus aureus. Applied Microbiology 24: 240-247. 
Hawthorne, S.B., Grabanski, C.B., Martin, E. \& Miller, D.J. (2000). Comparisons of Soxhlet extraction, pressurized liquid extraction, supercritical fluid extraction and subcritical water extraction for environmental solids: recovery, selectivity and effects on sample matrix. Journal of Chromatography 8: 421-433.

Ignat, I., Volf, I. \& Popa, V.I. (2011). A critical review of methods for characterisation of polyphenolic compounds in fruits and vegetables. Food Chemistry 12 : 1821-1835.

Kalsi, P.S. (2002). Spectroscopy of organic compounds $-5^{\text {th }}$ Edition, New Age and Allied (P) Ltd, Kolkata, India, pp. 719-724.

Kupradinun, P., Siripong, P., Chanpai, R., Piyaviriyagul, S., Rungsipipat, A. \& Wangnaitham, S. (2009). Effects of Rhinacanthus nasutus on colon carcinogenesis in mice. Asian Pacific Journal of Cancer Prevention 10: 103106.

Lai, P.K. \& Roy, J. (2004). Antimicrobial and chemopreventive properties of herbs and spices. Current Medicinal Chemistry 11: 1451-1460.

Magiorakos, A.P., Srinivasan, A., Carey, R.B., Carmeli, Y., Falagas, M.E., Giske, C.G. \& Paterson, D.L. (2012). Multidrugresistant, extensively drug-resistant and pandrug-resistant bacteria: an international expert proposal for interim standard definitions for acquired resistance. Clinical Microbiology and Infection 18: 268-281.

Pillay, M. \& Sturm, A.W. (2007). Evolution of the extensively drug-resistant F15/ LAM4/KZN strain of Mycobacterium tuberculosis in KwaZulu-Natal, South Africa. Clinical Infectious Diseases 45: 1409-1414.
Puttarak, P., Charoonratana, T. \& Panichayupakaranta, P. (2010). Antimicrobial activity and stability of rhincanthin rich Rhinacanthus nasutus extract. Phytomedicine 11: 323-327.

Sendl, A., Chen, J.L., Jolad, S.D., Stoddart, C., Rozhao, E. \& Kernann, M. (1996). Two new naphthoquinones with antiviral activity from Rhinacanthus nasutus. Jourmal of Natural Products 59: 808-811.

Shah, N.S., Wright, A., Bai, G.H., Barrera, L., Boulahbal, F., Martín-Casabona, N. \& Lumb, R. (2007). Worldwide emergence of extensively drug-resistant tuberculosis. Emerging Infectious Diseases 13: $380-385$.

Sukanya, S.L., Sudisha, J., Hariprasad, P., Niranjana, S.R., Prakash, S.H. \& Fathima, K.S. (2009). Antimicrobial activity of leaf extracts of Indian medicinal plants against clinical and phytopathogenic bacteria. African Journal of Biotechnology 8: 677-680.

Tadeg, H., Mohammed, E., Asres, K. \& Gebre-Mariam, T. (2005). Antimicrobial activities of some selected traditional Ethiopian medicinal plants used in the treatment of skin disorders. Journal of Ethnopharmacology 19: 168-175.

Thiyagarajan, P., Chandrasekaran, C.V., Deepak, H.B. \& Agarwal, A. (2011). Modulation of lipopolysaccharide induced pro-inflammatory mediators by an extract of Glycyrrhiza glabra and its phytoconstituents. Inflammopharmacology 19: 235-241.

Upendra, R.M., Sreenivasulu, M., Chengaiah, B., Ravikrishna, D., Jaganmohan, R.K., Sangeetha, K. \& Chetty, C.M. (2010). Rhinacanthus nasutus - A comprehensive review. International Journal of Pharmaceutical Research and Development 7: 115-123. 